\title{
Effects of Web Openings on the Effective Slab Widths in Composite Steel Beams
}

\author{
Mohammad A. A. Alsarraf and Hamdy Shehab El Din
}

\begin{abstract}
This paper deals with the behavior of composite beams with particular focus on the effects of web openings on the effective slab width, which is required for simplified structural analysis and design. Current design codes propose values for the effective width which are mostly a function of the beam span ignoring in this way the influence of other important parameters. In addition, effect of web opening is not established in the literature. Several 3D numerical simulations are conducted in this paper in order to illustrate these parameters and accordingly a new methodology is suggested for evaluating the effective width of the composite beams with web openings. The proposed approach is easier to apply in comparison with other existing methods based on stress integration, and provides effective width values which result in a more reliable representation of the actual beam state when simplified analysis is carried out. The application of the proposed revised method indicates that the effective width is influenced by the web opening, and this influence relates to the type of opening and the size of opening and, in many cases, the values obtained can significantly differ from those proposed design codes.
\end{abstract}

Index Terms-Effective width, composite beam, web openings, finite element modeling.

\section{INTRODUCTION}

In a composite section, in-plane shear strain in the slab (acting as a flange in the composite girder) under the applied bending causes the longitudinal displacements in the parts of the slab remote from the webs to lag behind those near the webs. This phenomenon, termed shear-lag, can result in an incorrect calculation of the displacement and extreme fiber stresses when using only the elementary theory of beam bending. The effective width concept has been introduced, widely recognized, and implemented into different codes of practice around the world as a simplified practical method for design and evaluation of structural strength and stiffness while accounting for shear-lag effects indirectly. Each code implements different ideas and approaches for specifying effective width.

While it is usually assumed that the plane sections remain plane in bending of a section, this assumption does not hold for short span beam with wide flanges since the shear lag effects causes nonlinear stress distribution over cross section. Sedlacek and Bild [1] suggested a simplified method for determination of the effective width due to shear lag effects. Amadio and Fragiacomo [2] evaluated the effective width for

Manuscript received June 29, 2014; revised August 12, 2014.

Mohammad A. A. Alsarraf is with Kuwait Ministry of Public Works, Construction Department, Kuwait (e-mail: alsarraf2007@gmail.com).

H. Shehab El Din is with Faculty of Engineering, Zagazig University, Egypt (e-mail: hshehabeldin@yahoo.com) steel-concrete composite beams and their paper they analyzed serviceability and other limit states. Through a parametric study in Abaqus they concluded that the actual codes, in general, do not provide appropriate results for elastic and ultimate limit state checks.

Chiewanichakorn et al. [3] investigated the effective width of steel-concrete composite bridge girders. They mentioned that as the spacing between the girders becomes larger, the beam theory does not apply to the composite beams since the longitudinal compressive stress in the flange will vary with distance from the girder web, the flange being more highly stresses over the web than in the extremities, which is called "shear lag".

In a separate experimental research program Amadio et al. [4] evaluated the effective width of composite steel-concrete beams. The research program included experimental testing of four specimens at the University of Trieste. Ahn et al. [5] evaluated the effective flange width provisions for composite steel bridges. The authors highlighted the distinct philosophies underlying the various effective width code expressions in the US, Britain, Canada, Japan, and the European Committee.

Lawson et al. [6] studied the design of composite asymmetric cellular beams and beams with large web openings. The design of composite asymmetric cellular beams is not fully covered by existing guidance but is an area of important practical application. The authors concluded that asymmetry of the cross-section of cellular beams is important in determining the in-plane moments that are developed in the web-post between openings. Castro et al. [7] assessed the effective slab widths in composite beams. They conducted several 3D numerical simulations in order to illustrate the influence of important parameters, such as the slab thickness, the beam span and the boundary conditions, on effective width and accordingly suggest a new methodology for evaluating the effective width. Macorinia et al. [8] conducted finite element modeling on long-term analysis of steel-concrete composite beams for evaluation of effective width. They presented a finite element model suitable for long-term analysis of steel-concrete composite beams. This comprehensive literature review shows that no finite element study has been done of the influence of the type and size of the web openings on the effective flange width in composite girders.

\section{Provisions for Effective Flange Width of COMPOSITE STEEL GIRDERS}

In elementary beam bending theory, it is assumed that the stresses are constant through the width of the beam. Although, 
this assumption may be valid for the thin flange of a steel beam, for the wide concrete flange of composite girders the stresses are not uniform. This variation of stresses, also called "shear-lag", is due to the in-plane shear strain in the plate. By replacing the actually acting flange width with an appropriate reduced uniformly stressed "effective" flange width, shear lag effects can be accounted for, and therefore elementary beam bending theory can be used.

Graphically, the three-dimensionally changing normal stress at a distance $x, \sigma_{x}=\sigma_{x}(y, z)$ is represented by its maximum value, shown as $\sigma_{x, \max }$ in Fig. 1 . The force effects on the flange are required to be the same for both cases as shown in Fig. 1.

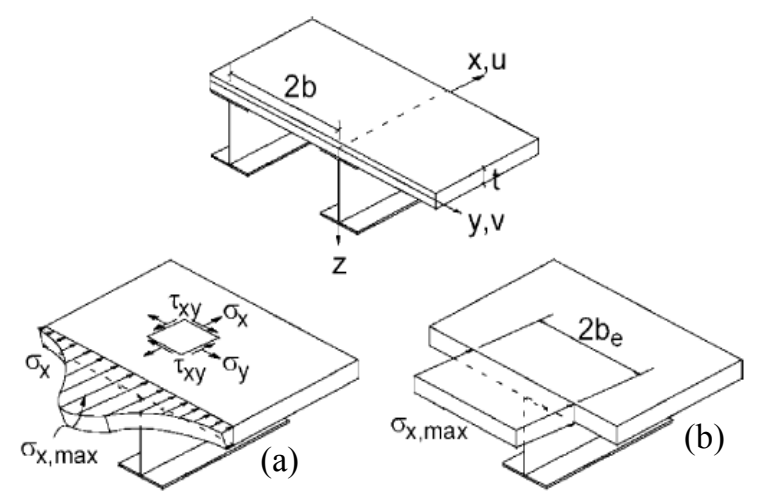

Fig. 1. II Concept of effective flange width. (a) actual stress distribution; (b) uniform stress distribution within effective flange width.

\section{A. Basic Formulation Code Provisions}

In this section effective width provisions from different codes are described and compared. For simplicity and convenience, AASHTO, BS 5400, Canadian, Japanese, and Eurocode 4 refer to "AASHTO LRFD Bridge Design Specification" in the US, "British Standard 5400-Steel, Concrete and Composite Bridges" in the UK, "Canadian Highway Bridge Design Code", "Design Specifications for Highway Bridges" in Japan, and "Design of Composite Steel and Concrete Structures, Part 2" in European Committee, respectively.

\section{B. AASHTO}

AASHTO contains two sets of provisions for effective flange width - namely, for interior and for exterior girders. Applying the "one-side" effective flange width concept makes it possible to reduce them into one set of provisions. For interior beams, the effective flange width may be taken as the least of: (1) one-quarter of the effective span length, (2) 12.0 times the average thickness of the slab, plus the greater of web thickness or one-half the width of the top flange of the girder, or (3) the average spacing of adjacent beams [AASHTO 4.6.2.6]. AASHTO specifies that effective flange width rules are used for determining resistance for all limit states. Referring to the AASHTO Standard Specifications, which describes "...effective width of the slab as a T-beam flange...', it can be understood that flexural behavior is the main concern of the provisions.

\section{C. $B S 5400$}

In Part 5 of BS 5400, the effective flange width ratios are defined in three tables, which cover simply-supported, cantilever, and internal (interior) spans of continuous beams (BSI-Part 5: 5.2.3). For each case, effective flange width ratios for mid span, quarter span, and support are specified for various values of girder spacing to span length, i.e., $b / l$. For the end (exterior) spans of continuous beams, the ratios from the simply-supported case with reduced span length, $0.9 l$, may be used (BSI-Part 5: 5.2.3.5). The effective flange width ratio at an internal support is obtained as the mean value of ratios obtained for each span adjacent to that support. For a cracked concrete flange, the ratio may be modified (BSI-Part 5: 5.2.3.7). Different ratios are specified for uniformly distributed and point loads in the tables, emphasizing difference of effective flange widths for point loads and uniformly distributed loads. For effective flange width ratios to be used in stress calculations on structural elements subjected to standard highway or railway loading, it is specified that ratios from uniformly distributed cases should be used (BSI-Part 5: 5.2.3.2). For overhang of exterior girders, $85 \%$ of overhang length should be used to look up the table.

\section{Canadian Specification}

In Canadian specification (CSA 2000.CSA Commentary 2001), a reduced cross-section defined by effective width formulation shall be used for calculations of bending resistances and bending stresses in slab-on-girder bridges and box-girder bridges having a concrete slab, and with steel or concrete girders (CSA 5.8.2.1). The same reduced section is used for both the service limit state and the ultimate limit state. The effective flange width consists of the sum of a central part and overhang (side) parts.

The major advantage of the Canadian specifications is in its simplicity. Only one simple formula is used to calculate the effective flange width for slab-on-I girders and box girders made of steel or concrete.

\section{E. Japanese Specification}

In Japanese specification (JRA, 1996), one-side effective flange width, $k$ is used to evaluate the effective flange width of beams and/or stringers in calculating stresses and displacements. Japanese provisions are based on analytical solutions, which date back to the 1950s.

\section{F. Eurocode 4}

In Eurocode 4 (1997), “action effects may be calculated by elastic analysis, even where the resistance of a cross-section is based on its plastic or nonlinear resistance". For serviceability limit states, elastic analysis should be used with appropriate corrections for nonlinear effects such as cracking of concrete. When elastic analysis is used, a constant effective width may be assumed over the whole length of each span. Similar to the Canadian specification, Eurocode 4 also divides the effective flange width into a central part and side parts. However, Eurocode 4 uses the distance between outside shear connectors as the central part of the effective flange width, which requires the design detail of shear connectors. The one-side effective flange width is determined as the least of (1) 1/8 of span length, or (2) the distance from the outside shear connector to a point mid-way between adjacent webs. Eurocode 4 also considers the 
reduction of effective width at the end of the span. Thus, a modification factor is applied to the one-side effective width at the end supports.

\section{G. Comparison of Provisions}

Based on the descriptions in the previous section, characteristics of each provision are summarized and compared in Table I. The full width is considered effective after $L / b$ reaches 8 for Eurocode 4, 15 for the Canadian, and 20 for the Japanese specification. Because of the thickness limitation in AASHTO, the effective flange widths take on different values for different deck thickness. Eurocode 4 uses almost the same definition as in AASHTO except for the latter's thickness limitation. Therefore, the values from Eurocode 4 are expected to be the same as the results of AASHTO specifications without the thickness limitation.

Because the stress distribution in the deck changes with the amount of load, the effective flange width at the service limit state is different from that at the strength (ultimate) limit state. For example, BS 5400 distinguishes between the two limit states, and the reduced (effective) width is used only for the service limit state. AASHTO specifications, however, use the same effective flange width for both the service and strength limit state. The Canadian provisions also use the same effective width for stress and capacity calculation (CSA, 2000). The effective flange width for the strength limit state is in fact larger than that for the service limit state. It has been thought that underestimation of effective flange width is conservative for the resistance of a beam, so simplicity with some loss of accuracy may be acceptable (Johnson, 1993).

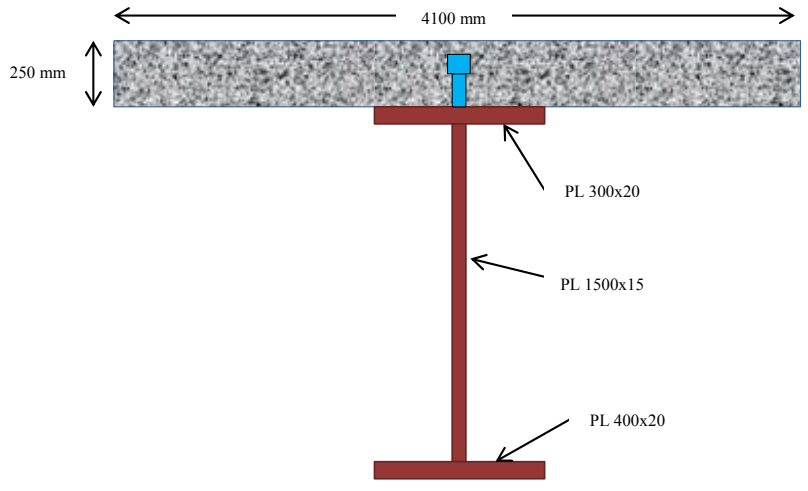

Fig. 2. Cross section of the basic composite beam for modeling.

\section{DeVelopment of Analytical Model}

\section{A. Geometry of the Base Model}

The composite girder chosen as the base model is a built up steel girder with $400 \mathrm{~mm} \times 20 \mathrm{~mm}$ bottom flange, $1500 \mathrm{~mm}$ $\times 15 \mathrm{~mm}$ web, and $300 \mathrm{~mm} \times 20 \mathrm{~mm}$ top flange, and a 250 $\mathrm{mm}$ thick by $4100 \mathrm{~mm}$ wide reinforced concrete slab. The slab is connected to the top flange with shear connectors. The length of the simply supported composite girder is $40 \mathrm{~m}$. The cross section of this composite girder is shown in Fig. 2. This cross section was chosen based on common composite girder design for bridges with this span. The software used for finite element modeling and analysis was Strand 7.

TABLE I: COMPARISON OF PROVISIONS

\begin{tabular}{|c|c|c|c|c|c|}
\hline Effective Width Provisions & AASHTO & BS 5400 & Canadian & Japanese & Eurocode 4 \\
\hline Distinguish UDL vs. point load & $N$ & $Y^{a}$ & $N$ & $Y$ & $N$ \\
\hline Distinguish exterior vs. interior girder & $Y$ & $Y$ & $N$ & $N$ & $N$ \\
\hline Expressed as one-sided & $N$ & $Y$ & $Y_{c}$ & $Y$ & $Y_{c}$ \\
\hline Distinguish $M(+)$ region from $M()$ region & $N$ & $Y$ & $N$ & $Y$ & $N$ \\
\hline Distinguish I girder from box girder & $Y^{d}$ & $N$ & $N$ & $N / A$ & $N / A$ \\
\hline Distinguish strength (ultimate) vs. service & $N$ & $Y^{c}$ & $N$ & $N$ & $Y f$ \\
\hline Value modified at supports & $N$ & $Y$ & $N$ & $N$ & $Y$ \\
\hline Value modified for concrete cracking & $N$ & $Y$ & $N$ & $N$ & $Y$ \\
\hline \\
\hline \multicolumn{6}{|c|}{${ }^{a}$ Use uniformly distributed load (UDL) case for highway bridges. } \\
\hline \multicolumn{6}{|c|}{ Use PL case especially for internal supports of continuous girders. } \\
\hline \multicolumn{6}{|c|}{ Effective flange width is divided into certral part and side parts. } \\
\hline \multicolumn{6}{|c|}{ Use different provisions for concrete segmental box-girder bridges. } \\
\hline \multicolumn{6}{|c|}{ Use effective flange width for service limit state, use full width for ultimate limit state. } \\
\hline
\end{tabular}

Due to the geometry of the model and thickness of the elements (flanges, web, and slab) it was decided to use shell elements to model the components of the composite girder.

Using the described geometry and shell elements, a base finite element model was developed. The model represents a $40 \mathrm{~m}$ simply supported span. Extruded view of the 3D base finite element model is shown in Fig. 3.

\section{B. Mesh Sensitivity Analysis}

It has been shown that computational cost is proportional to the number of elements and roughly inversely proportional to the smallest element dimension in explicit analysis method, For example, in a three dimensional model with uniform square elements, if the mesh is refined by a factor of 2 in all three dimensions, the computational cost increases by a factor of 16 for explicit method. The optimized mesh size is the one for which accuracy of the results and analysis time is in balance, and reasonably accurate results are obtained for reasonable analysis time/cost. The optimal mesh size can also be defined as the mesh size which gives the least analysis error. It should be noted that smaller mesh sizes do not necessarily provide more accurate results, because for meshes smaller than a certain size numerical errors due to the size and number of elements govern the results and error increases.

In order to find the optimum mesh size for the finite element models in this study, different mesh sizes were used and the deformation of the model was compared with the hand calculations based on engineering methods and the percentage of error was drawn versus the number of elements 
in the model. In addition, the analysis time for each method was documented and drawn versus the number of elements. Since the error levels are in acceptable range $(\sim 3 \%)$ and the computational time is reasonable $(\sim 9 \mathrm{sec}$.$) , the model with$ 5,600 elements was chosen as the optimum mesh size model.

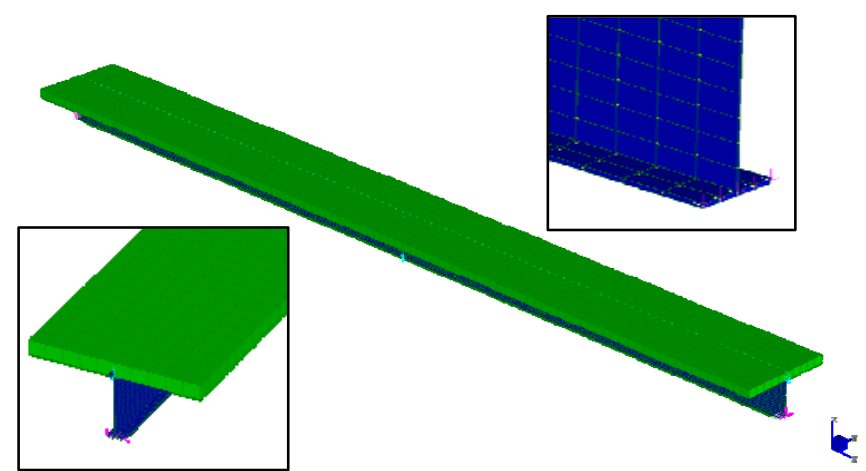

Fig. 3. 3D finite element model of the base simply supported composite BEAM.

\section{Configuration of the Finite Element Models}

Finite element models encompassed composite models with rectangular openings. These models consisted of four tiers of models as listed in Table II.

TABLE II: PERCENTAGE OF WEB OPENING FOR SERIES 1 AND 2

\begin{tabular}{|c|c|}
\hline Tier & $\begin{array}{c}\text { \% of Web Rectangular } \\
\text { Opening (Series } 1)\end{array}$ \\
\hline Tier 1 & $0 \%$ (No opening) \\
\hline Tier 2 & $14 \%$ \\
\hline Tier 3 & $33 \%$ \\
\hline Tier 4 & $51 \%$ \\
\hline
\end{tabular}

Fig. 4 illustrates these tiers for the composite girders with rectangular openings.

\section{Models for Parametric Studies}

In order to perform a parametric study to determine the influence of different factors on the effective width of composite girders with openings, each tier of the abovementioned series encompassed multiple groups of models in which different characteristics of the models (e.g. slab thickness, slab width, span length, type of loading) were changed and the results were interpreted and compared with the base models. Each tier (listed in Table II) included the variables and constants listed in Tables III to Table VI.

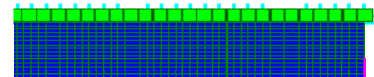

a) Tier 1 models: web with no opening.

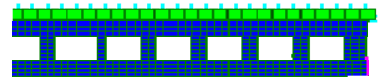

c) Tier 3 models: $33 \%$ web opening.

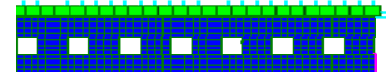

b) Tier 2 models: 14\% web opening.

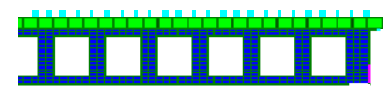

d) Tier 4 Models: 51\% Web Opening.

Fig. 4. Percentage of opening for different tiers of series 1 FE models (webs with rectangular openings).

TABLE III: GROUP A, VARIABLE SLAB THICKNESS

\begin{tabular}{|l|l|}
\hline \multicolumn{1}{|c|}{ Constants } & \multicolumn{1}{c|}{ Variables } \\
\hline Slab width: $4100 \mathrm{~mm}$ & Slab Thickness: $100 \mathrm{~mm}$ \\
Span length: $40 \mathrm{~m}$ & Slab Thickness: $150 \mathrm{~mm}$ \\
Point load & Slab Thickness: $200 \mathrm{~mm}$ \\
\hline
\end{tabular}

TABLE IV: GROUP B, VARIABLE SLAB WIDTH

\begin{tabular}{|l|l|}
\hline \multicolumn{1}{|c|}{ Constants } & \multicolumn{1}{|c|}{ Variables } \\
\hline Slab Thickness: $250 \mathrm{~mm}$ & Slab Width: $2460 \mathrm{~mm}$ \\
Span length: $40 \mathrm{~m}$ & Slab Width: $4100 \mathrm{~mm}$ \\
Point load & Slab Width: $5740 \mathrm{~mm}$ \\
\hline
\end{tabular}

TABLE V: GROUP C, VARIABLE SPAN LENGTH

\begin{tabular}{|l|l|}
\hline \multicolumn{1}{|c|}{ Constants } & \multicolumn{1}{c|}{ Variables } \\
\hline Slab Thickness: $250 \mathrm{~mm}$ & Span Length: $10 \mathrm{~m}$ \\
Span Width: $4100 \mathrm{~m}$ & Span Length: $20 \mathrm{~m}$ \\
Point load & Span Length: $30 \mathrm{~m}$ \\
& Span Length: $40 \mathrm{~m}$ \\
& Span Length: $50 \mathrm{~m}$ \\
\hline
\end{tabular}

TABLE VI: GROUP D, TYPE OF LOAD

\begin{tabular}{|l|l|}
\hline \multicolumn{1}{|c|}{ Constants } & \multicolumn{1}{c|}{ Variables } \\
\hline Slab Thickness: $250 \mathrm{~mm}$ & Point Load \\
Span Width: $4100 \mathrm{~m}$ & Axle Load (Linear Transverse) \\
Span Length: $40 \mathrm{~m}$ & Uniform Load \\
& \\
\hline
\end{tabular}

\section{PARAMETRIC Study AND Discussion OF Finite ELEMENT MODELING RESULTS}

\section{A. Definition of Effective Width}

The definition of effective width is based on the stress distributions in the slab, which is directly related to the shear lag phenomenon as shown in Fig. 1. In this case, the effective width $\left(b_{\text {eff }}\right)$ is considered as the width of slab that sustains a force equal to that in the actual slab, assuming the longitudinal stresses to be constant across the effective slab width and equal to the peak stress over the steel beam centerline.

\section{B. Stress Analysis for Composite Girders}

\section{1) Series A - slab thickness}

Based on the results of the study, for thicker slabs, the shear stiffness is higher and therefore the presence of shear lag is attenuated. It is clear that when the slab thickness is smaller, the variation of the longitudinal stress is relatively more evident. However, the influence of this parameter is not as significant as that observed for the slab width. It appears that for larger rectangular openings on the web, this ratio increases and, for each opening, this ratio is larger for thicker slabs, except for $33 \%$ and $51 \%$ web openings where this phenomena reverses in Fig. 5.

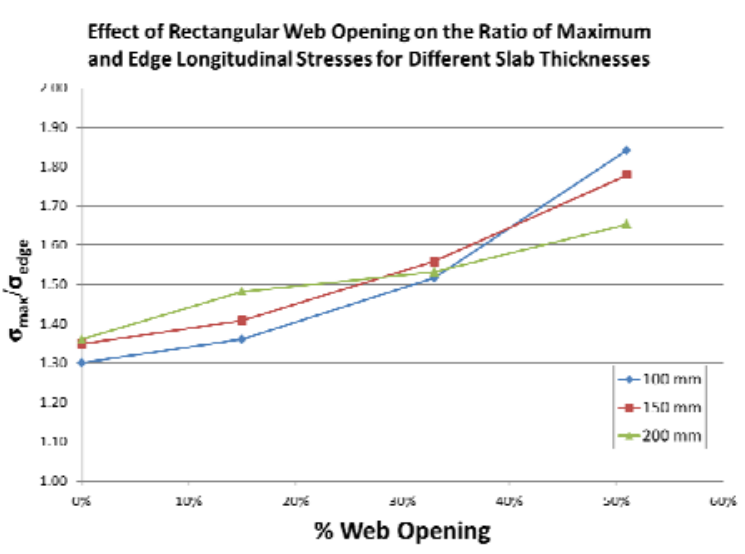

Fig. 5. Effect of rectangular web opening on the ratio of maximum and edge longitudinal stresses for different slab thicknesses. 


\section{a) Series $B$ - slab width}

This parameter is directly related to the in-plane shear stiffness of the slab. The larger the slab width, the lower the shear stiffness. As expected, the shear lag effect is more evident for larger slab widths. It appears that for larger rectangular openings on the web, this ratio increases and, for each opening, this ratio is larger for wider slabs (Fig. 6).

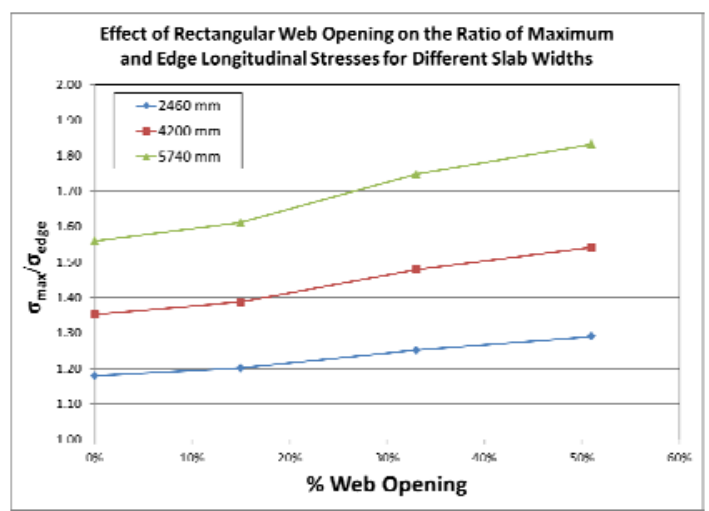

Fig. 6. Effect of rectangular web opening on the ratio of maximum and edge logitudinal stresses for different slab widths

\section{b) Series $C$ - span length}

It appears that for larger rectangular openings on the web, this ratio increases and, for each opening, this ratio is larger for shorter spans. There is a significant increase between span length of $20 \mathrm{~m}$ and $10 \mathrm{~m}$ (Fig. 7).

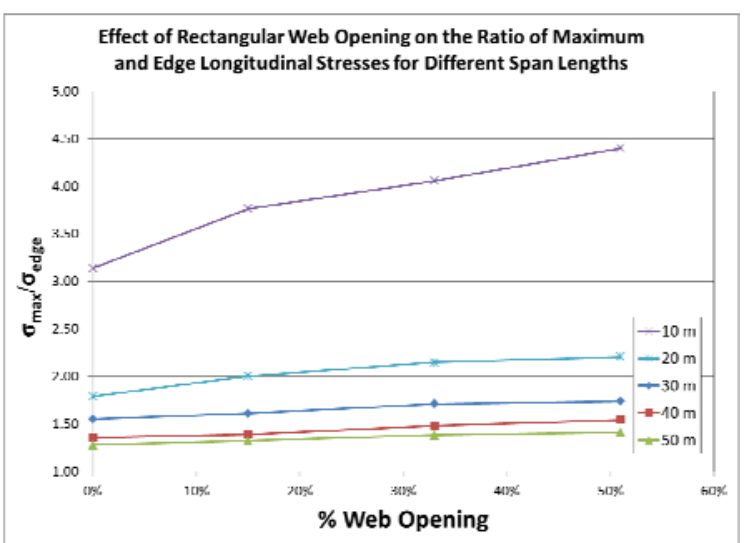

Fig. 7. Effect of rectangular web opening on the ratio of maximum and edge logitudinal stresses for different span lengths.

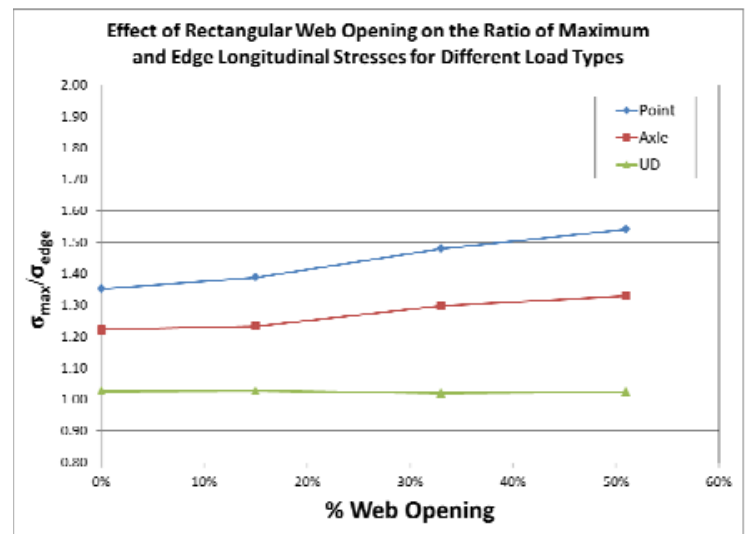

Fig. 8. Effect of rectangular web opening on the ratio of maximum and edge logitudinal stresses for different load types

\section{c) Series D-type of load}

It appears that as the load changes from a point load to axle load (transverse linear) to uniformly distributed load, $\sigma / \sigma_{\max }$ becomes closer to 1.0 along the width if the slab and remains relatively unchanged versus the percentage of opening. However, $\sigma_{\max } / \sigma_{\text {edge }}$ increases between UD, Axle and Point loads for all the cases. This suggests that effective width is almost insensitive to the web openings for the composite girders under uniformly distributed loads, but it gets more sensitive as the type of load changes (Fig. 8). Evident from the significant difference between the stress distributions for point, axle, and uniform loads, if effective widths are derived on the basis of stress calculations, the resulting values can be considerably different depending on the load type.

\section{CONCLUSION}

This paper focused on the behavior of composite beams with rectangular openings, and how web openings would impact the effective width of such beams. It was concluded that web openings influence the effective width of composite beams. Existing equations fall short of providing accurate effective width values, and they should be revised to account for web openings.

\section{REFERENCES}

[1] G. Sedlacek and S. Bild, "A Simplified method for the determination of the effective width due to shear lag effects," J. Construct. Steel Research, vol. 24, pp. 155-182, 1993.

[2] C. Amadio and M. Fragiacomo, "Effective width evaluation for steel-concrete composite beams," Journal of Constructional Steel Research, vol. 58, pp. 373-388, 2001.

[3] M. Chiewanichakorn, A. J. Aref, S. S. Chen, and I. Ahn, "Effective flange width definition for steel-concrete composite bridge girder," Journal of Structural Engineering, vol. 130, no. 12, pp. 2016-2031, 2004.

[4] C. Amadio, C. Fedrigo, M. Fragiacomo, and L. Macorini, "Experimental evaluation of effective width in steel-concrete composite beams," Journal of Constructional Steel Research, vol. 60, pp. 199-220, 2004.

[5] I. Ahn, M. Chiewanichakorn, S. S. Chen, and A. J. Aref, "Effective flange width provisions for composite steel bridges," Engineering Structures, vol. 26, pp. 1843-1851, 2004.

[6] R. M. Lawson, J. Limb, S. J. Hicks, and W. I. Simms, "Design of composite asymmetric cellular beams and beams with large web openings," Journal of Constructional Steel Research, vol. 62, pp. 614-629, 2005.

[7] J. M. Castro, A. Y. Elghazouli, and B. A. Izzuddin, "Assessment of effective slab widths in composite beams," Journal of Constructional Steel Research, vol. 63, pp. 1317-1327, 2007.

[8] L. Macorinia, M. Fragiacomob, C. Amadioa, and B. A. Izzuddinc, "Long-term analysis of steel-concrete composite beams: FE modelling for effective width evaluation," Engineering Structures, vol. 28, pp. 1110-1121, 2006.

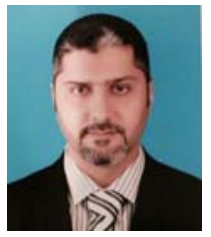

Mohammad A. A. Alsarraf is currently working at the Ministry of Public Works in Kuwait as a specialist projects engineer.

Mr. Alsarraf graduated from Kuwait University with bachelor's and master's degree in civil engineering in 1999 and 2003, respectively. He is completing his research in structural engineering pursuing his Ph.D. degree at Zagazig University in Egypt, and will be graduating in 2014.

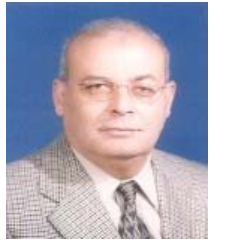

Hamdy Shehab El Din is a professor of civil engineering at Zagazig University in Egypt. He also serves as the dean of the Faculty of Engineering.

He received his Ph.D. from Cairo University in 1990 with a research on waffled slabs without shear reinforcement. His research area is focused on issues related to structural engineering. 